\title{
Numerical Study of Ignition and Combustion of Partially Cracked Kerosene in a Mach 2.5 Supersonic Model Combustor
}

\author{
Fengquan Zhong ${ }^{1}$, Lihong Chen ${ }^{2}$, Xinyu Chang ${ }^{3}$
}

\begin{abstract}
In this paper, unsteady process of ignition of partially cracked kerosene in a Mach 2.5 supersonic model combustor was studied numerically. The reaction flow was solved with SST k- $\omega$ turbulence model and a kinetic mechanism of kerosene reduced from a detailed mechanism. Eddy dissipation concept is used to model the turbulence/chemistry interaction and In Situ adaptive tabulation algorithm applied for the acceleration of numerical integrations. Based on the present results, time evolutions of ignitions of partially cracked kerosene are described and the temporal and spatial changes of main radicals and products are provided. It is found that the pilot hydrogen supplies a radical pool of $\mathrm{OH}$ in the cavity that promotes the ignition of kerosene and stabilizes the flame. For the present flow and fuel conditions, ignition of partially cracked kerosene is completed at a physical time of approximately 5.6ms. However, for uncracked gaseous kerosene, the finish time of ignition is significantly longer. It is believed that the HCO radical formed by the oxidation of $\mathrm{C} 2 \mathrm{H} 4$, one of the major products of kerosene cracking, attributes to the ignition acceleration for partially cracked kerosene.
\end{abstract}

\section{Nomenclature}

$\mathrm{T}=$ static temperature of the combustor flow

$\mathrm{P}=$ static pressure of the combustor flow

$\mathrm{Y} \quad=$ mass fraction

$\omega \quad=$ formation rate of species

$\Delta \mathrm{y} \quad=$ gird spacing in the normal direction

subscript

in $\quad=$ combustor inlet

$\mathrm{w} \quad=$ wall

$+\quad=$ wall units

\section{Introduction}

Hydrocarbon fuels such as aviation kerosene are commonly used in long-run scramjets such as X-51A ${ }^{[1]}$. It, however, imposes significant challenges in ignition reliability and combustion efficiency due to the complicated thermophysical properties and long ignition time of the fuel ${ }^{[2]}$. It is known that hydrocarbon fuel such as kerosene consists of hundreds of species and its ignition delay time is significantly large and may be hundreds times that of hydrogen of the same conditions. The long ignition delay time makes ignition and sufficient combustion difficult

\footnotetext{
${ }^{1}$ Associate Professor, State Key Laboratory of High Temperature Gas Dynamics, Institute of Mechanics, Chinese Academy of Sciences, Beijing, 100190, Email: fzhong@imech.ac.cn

${ }^{2}$ Professor, State Key Laboratory of High Temperature Gas Dynamics, Institute of Mechanics, Chinese Academy of Sciences, Beijing, 100190

${ }^{3}$ Professor, State Key Laboratory of High Temperature Gas Dynamics, Institute of Mechanics, Chinese Academy of Sciences, Beijing, 100190
} 
especially in supersonic flow since the residence time of fuel is comparable to the characteristic time of reaction or even smaller.

Most of the previous numerical studies on supersonic combustion are pertinent to hydrogen ${ }^{[3,4]}$ or small hydrocarbons such as methane and ethylene ${ }^{[5,6]}$. So far, there have been very few researches about supersonic combustion of hydrocarbon fuels and to the authors' knowledge, the available reports are limited to steady calculation ${ }^{[7]}$. The lack of numerical studies on hydrocarbon fuels partly attributes to the complexity of the flow and reaction that raises numerical difficulties and computational expenses dramatically. As we know, an effective numerical study of supersonic combustion of kerosene requires a robust upwind scheme with high accuracy and a qualified turbulence model as well as a kinetic mechanism that can describe the interested chemical process and at the same time is acceptable for computation. Furthermore, considering the relatively large turbulence intensity in supersonic flow, especially in the vicinity of cavity or rearward facing step (They are widely used for ignition and flame holding in supersonic combustors), the interaction between turbulence and reactions must be modeled ${ }^{[8]}$. In this paper, ignition of partially cracked kerosene in a supersonic model combustor was numerically simulated with a SST k- $\omega$ model with compressibility and low Reynolds number corrections and with a reduced kinetic mechanism based on the detailed mechanism of kerosene proposed by P. Dagaut ${ }^{[9]}$. The chemistry-turbulence interaction was modeled by eddy dissipation concept developed by B. F. Magnussen ${ }^{[10]}$.

The objective of the paper is to study the effect of cracking on ignition. For a realistic long-run scramjet, regenerative cooling using on-board fuel is widely used for thermal management ${ }^{[11]}$. In a regenerative cooling system, the fuel will flow through cooling channels of the engine wall before injected into combustor. The temperature of fuel at the exit of the injector would reach a temperature range of $800 \mathrm{~K}-950 \mathrm{~K}$ and the fuel has been partially decomposed into small hydrocarbons ${ }^{[12]}$. Cracking of fuel into small molecules has great benefits not only for the fuel/air mixing and combustion, but also for the cooling since extra heat sink capacity can be obtained due to endothermicity of the cracking ${ }^{[13]}$. Thus, investigation of the effect of cracking on fuel ignition and combustion has importance in both academic and engineering issues. In this paper, the cracking effect on ignition delay time is discussed first. Then numerical simulations of ignition process of partially cracked and uncracked gaseous kerosene and their comparisons are presented.

\section{Numerical Method}

Finite volume method is used to solve Navier-Stokes equations and transport equations of species. AUSM+ scheme ${ }^{[14]}$ was applied for spatial discretization of the convective flux terms. Viscous fluxes are approximated by a $2^{\text {nd }}$-order central scheme and the time advancement is calculated by implicit Euler method. The SST k- $\omega$ model with compressibility and low Reynolds number corrections was employed for the simulation of turbulence. The perfect gas assumption is used and two 4th-order polynomials as function of temperature are applied to calculate the specific heats in temperature ranges of $300 \mathrm{~K}-1000 \mathrm{~K}$ and of $1000 \mathrm{~K}-5000 \mathrm{~K}$ respectively. Viscosity and thermal conductivity of species are calculated by kinetic theory with pre-given Lennard-Jones characteristic length and energy parameter. Mass diffusions are determined by the Fick's law and a turbulent Schmidt number is set as 0.7 .

To validate the numerical method, a jet of Nitrogen from a wall injector into a Mach 2.61 supersonic airflow was calculated and the normalized wall pressure is plotted in Figure 1 (a) with a comparison to experimental measurements ${ }^{[15]}$. A good agreement is found in the figure. The bow shock and flow separation due to the injection and a Mach barrel structure of the jet are also clearly simulated, but they are not presented here due to limit in pages. Since cavity is often used in supersonic combustors, a cavity with a length-to-height ratio of 5 in a Mach 3 supersonic flow is calculated. Figure 1 (b) gives the distribution of wall pressure as well as the result reported by M. R. Gruber et. al. ${ }^{[16]}$. The present numerical result agrees well with that of Gruber's. The two validations indicate that the presently used numerical scheme and mesh are qualified for the simulation of supersonic mixing flow. 
Figure 2 shows the 2-dimensional model combustor with dimensions. The height of the combustor entrance is $50 \mathrm{~mm}$ and the total length of the combustor is $860 \mathrm{~mm}$. The combustor consists of a constant area section upstream of the cavity and a divergent section with an angle of $2.4^{\circ}$ downstream of it. Kerosene is injected on both the top and the bottom walls at a location $61 \mathrm{~mm}$ upstream of the cavity as indicated in the figure. Pilot hydrogen was injected at a location $11 \mathrm{~mm}$ upstream of the cavity to initiate the fuel ignition. The cavity has a length-to-height ratio of 8 with an aft ramp angle of $27^{\circ}$. The computational domain is half of the combustor due to the symmetry of the flow in the normal direction. The flow condition at the entrance of the combustor is given as follows: Mach number is 2.5 , total temperature is $1700 \mathrm{~K}$ and static pressure is $67 \mathrm{kPa}$. The pilot hydrogen is injected at a pre-set total pressure of 2.3 atmospheres and at a total temperature of $300 \mathrm{~K}$. The uncracked and partially cracked kerosene are injected at a pre-set total pressure of 3 atmospheres and at varied total temperatures according to the cracked and the uncracked temperatures. The fuel/air equivalence ratio of the partially cracked kerosene is about 0.3 .
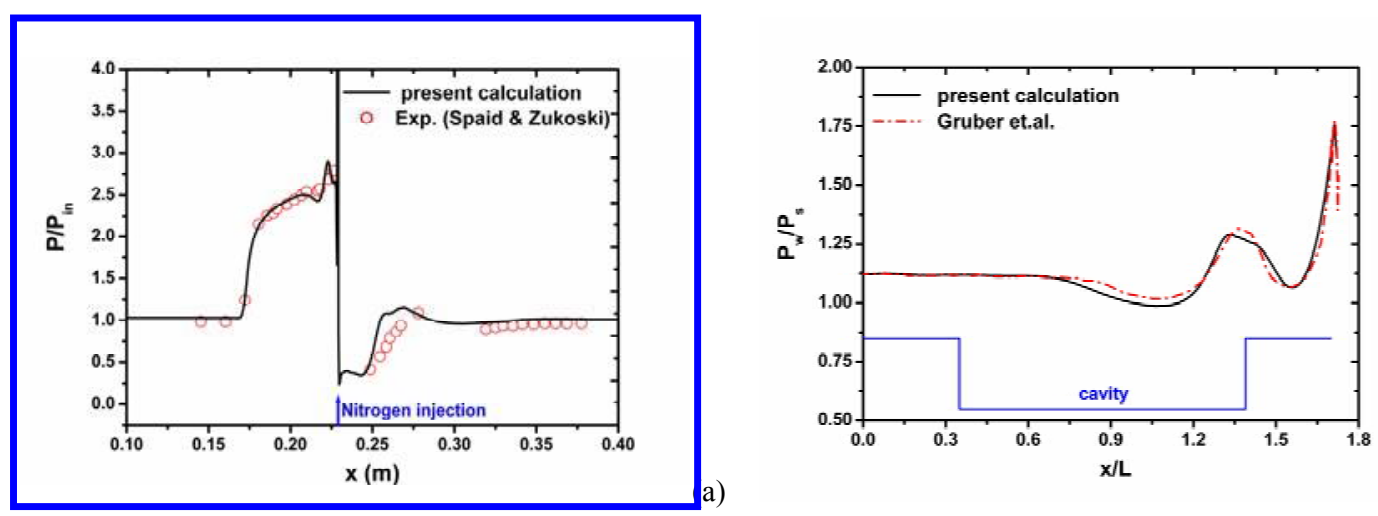

Figure 1 Validation of the numerical method (a): distribution of normalized wall pressure of a jet flow, (b): distribution of normalized wall pressure of a cavity flow

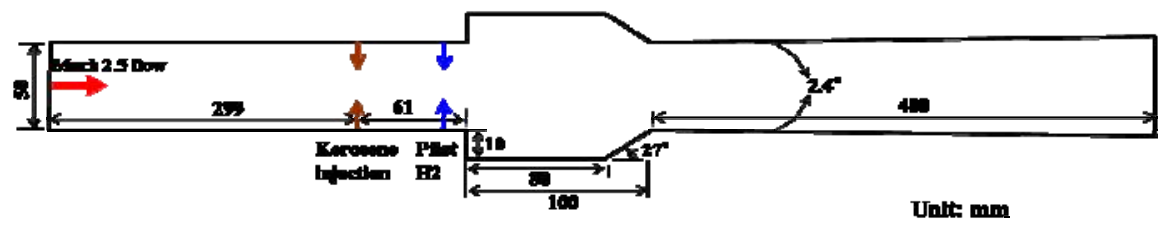

Figure 2 Schematic diagram of a Mach 2.5 supersonic combustor with injections of kerosene and pilot hydrogen

The total mesh is 63,000 with 14,000 grids in the cavity. The first grid point from the wall is at $\Delta y^{+} \leq 1$ and there are 8 points below $y^{+}=10$ for a good mesh resolution near the wall. The mesh dependency was investigated with doubled and half mesh points. It is found the presently used mesh size is an appropriate one.

The combustion/turbulence interaction is modeled by the method of eddy dissipation concept (EDC) ${ }^{[10]}$. The key idea of EDC is that chemical reactions with finite rate occur in typical vortices of turbulent flow and reaction rate is controlled by characteristic times of both the kinetic mechanism and the turbulence. With EDC model, kinetic mechanism can be fully coupled to the flow and temperature solver. However, kinetic mechanism is inevitably somewhat stiff and numerical integrations would become extremely computationally costly. To solve the problem, In Situ adaptive tabulation (ISAT) algorithm proposed by S. Pope ${ }^{[17]}$ is implemented to accelerate integrations. 


\section{Kinetic Mechanism of Kerosene}

A three-specie surrogate proposed by Fan et. al. for China No.3 aviation kerosene ${ }^{[18]}$ is used in the present study. The surrogate is comprised of (molar fraction) 49\% n-decane, 44\% 1,3,5-trimethycyclohexane and 7\% n-propylbenzene. It is found to be relatively accurate for the evaluation of thermodynamic and transport properties of the China kerosene.

The kinetic mechanism ${ }^{[19]}$ used in the calculation is reduced via quasi-steady-state assumption (QSS) from a detailed mechanism (207species, 1592reactions) proposed by P. Dagaut ${ }^{[9]}$. Species of the reduced mechanism are $\mathrm{NC} 10 \mathrm{H} 22, \mathrm{PHC} 3 \mathrm{H} 7, \mathrm{CYC} 9 \mathrm{H} 18, \mathrm{H} 2, \mathrm{O} 2, \mathrm{H}, \mathrm{O}, \mathrm{OH}, \mathrm{CO}, \mathrm{CO} 2, \mathrm{H} 2 \mathrm{O}, \mathrm{CH} 3, \mathrm{C} 2 \mathrm{H} 2, \mathrm{C} 2 \mathrm{H} 5, \mathrm{C} 2 \mathrm{H} 4, \mathrm{CH} 2 \mathrm{O}, \mathrm{C} 3 \mathrm{H} 6$ and N2. It is worthy mentioning that the reduced mechanism is different from commonly used multiple-steps models with pre-given reaction parameters. The reaction rates of the reduce mechanism are coupled and for each step, it is determined by all the species and flow conditions via matrix operation. Hence, simple equations such as Arrehenius formula can not be used to determine the reaction rates.

Figure 3 (a) plots the ignition delay time (atmospheric condition, fuel/air equivalence ratio is 1 ) as a function of temperature determined by the detailed mechanism, the reduced mechanism as well as by the experimental data ${ }^{[20]}$ respectively. A good agreement is found for all of results. Fig. 3 (b) gives the time evolution of $\mathrm{CH} 3$ and $\mathrm{OH}$ for a perfectly stirred reaction (PSR). As shown in the figure, results obtained by the reduced mechanism are very close to those by the detailed mechanism, indicating good performance of the reduced mechanism.

To study the effect of cracking on ignition, a cracking mechanism that kerosene decomposes into hydrogen and ethylene ${ }^{[21]}$ is considered. It represents an optimized catalytic cracking that can provide maximum endothermicity due to large percentage of unsaturated product. The ignition delay times of uncracked kerosene and of $20 \%, 50 \%$ (mass fraction) cracked kerosene are presented in Figure 4. As shown in the figure, the ignition delay time decreases as cracking percentage increases, especially at a temperature higher than $1100 \mathrm{~K}$. The reduced ignition delay time, of course, is in favor of ignition and combustion.
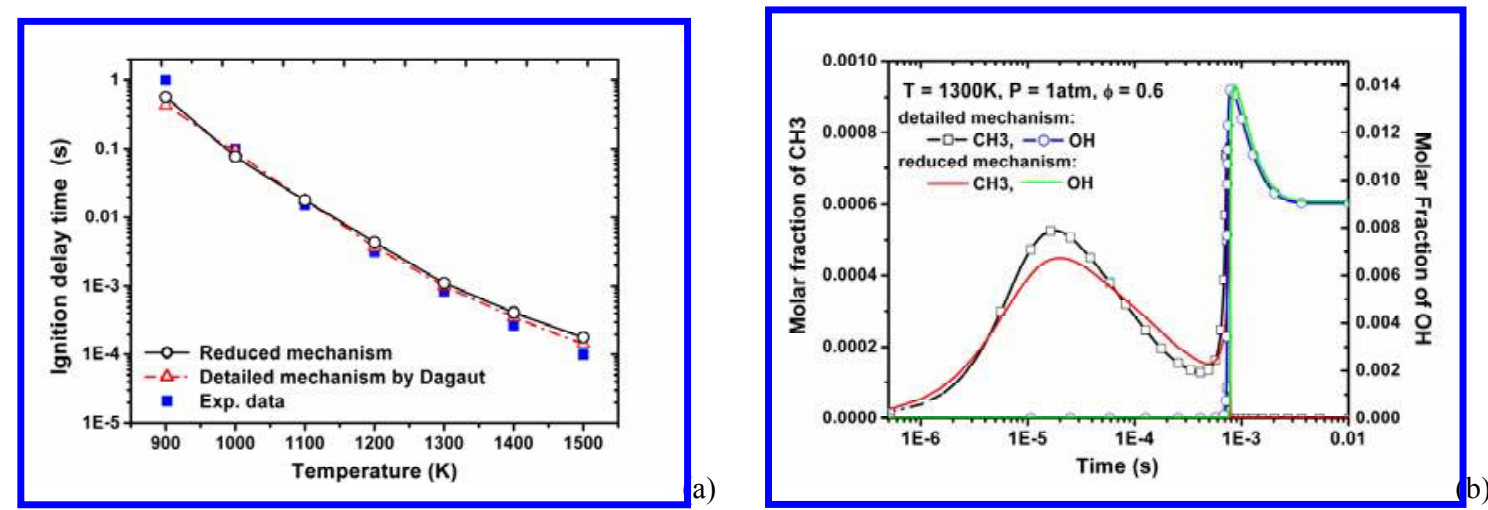

Figure 3 (a): Ignition delay time of kerosene as a function of temperature at atmospheric condition and a fuel/air equivalence ratio of 1, (b): time evolution of $\mathrm{OH}$ and $\mathrm{CH} 3$ for PSR at temperature and pressure of $1300 \mathrm{~K}$ and $1 \mathrm{~atm}$ and with a fuel/air equivalence ratio of 0.6 


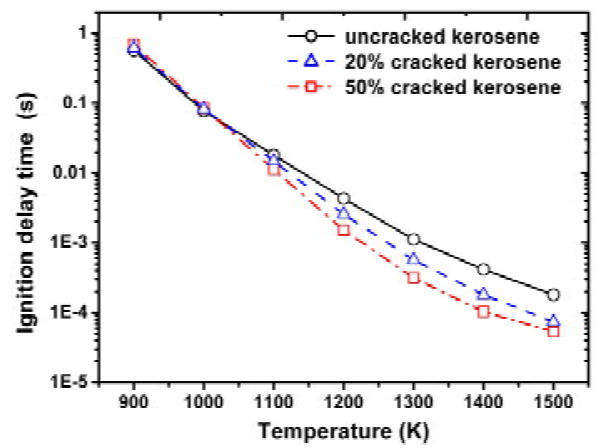

Figure 4 Ignition delay time of uncracked and partially cracked kerosene at atmospheric condition and a fuel/air equivalence ratio of 1

\section{Results and Conclusions}

\section{A. Ignition of partially cracked kerosene}

Combustion of the pilot hydrogen is first simulated. The computational time for hydrogen is 3.6 milliseconds and a steady state has been reached. The $50 \%$ cracked kerosene is then injected into the mainflow. In this paper, time is recorded from the beginning of the kerosene injection.

The total computational time for kerosene is 7 milliseconds. Figure 5 presents a time development of the contours of static temperature. The initial high temperature in the cavity is caused by the combustion of hydrogen. The kerosene jet diffuses and enters the cavity as time evolves. At $t=2.6 \mathrm{~ms}-3.6 \mathrm{~ms}$, significant heat release corresponding to a high temperature region is observed just downstream of the cavity. The region of the major heat release extends both downstream and upstream during a period of $\mathrm{t}=3.6 \mathrm{~ms}-5.6 \mathrm{~ms}$ and at $\mathrm{t}=5.6 \mathrm{~ms}$, the ignition approaches completion and a steady combustion is nearly established.
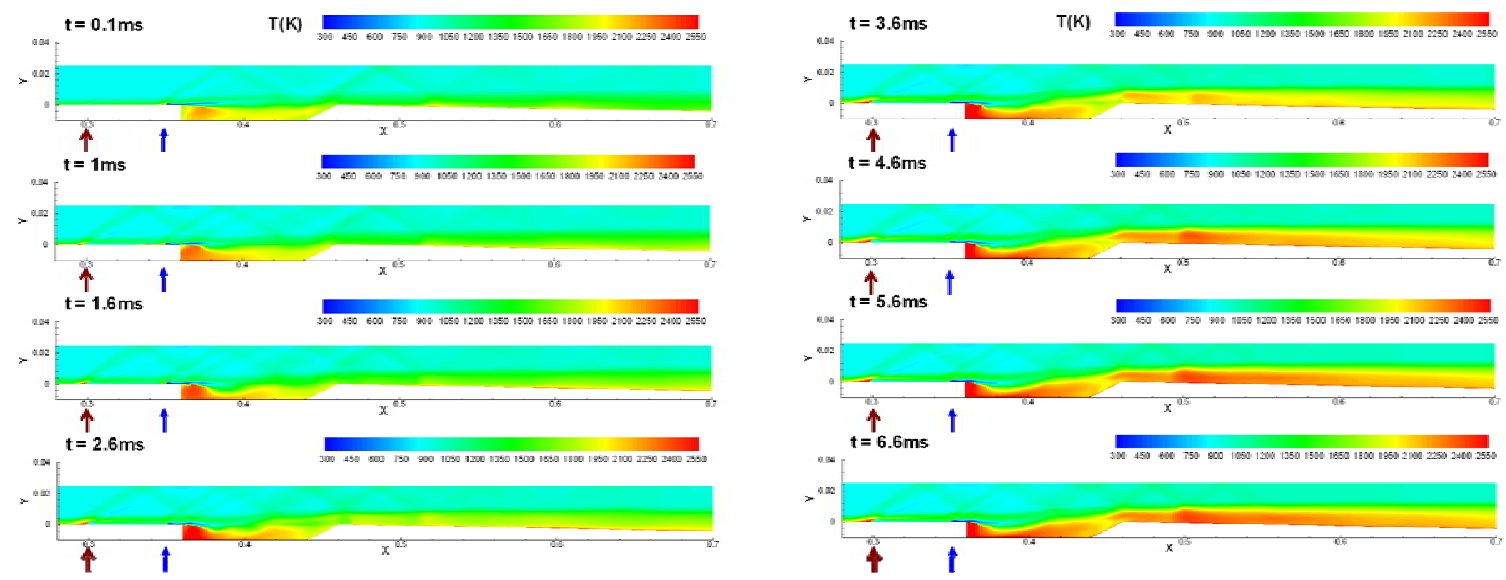

Figure 5 A sequence of static temperature contours for partially cracked kerosene (The two arrows in the figures denote the location of kerosene injection (the first one) and the location of hydrogen injection (the second one)

The time change of mass fraction of $\mathrm{CH} 3\left(Y_{\mathrm{CH} 3}\right)$ is presented in Figure 6. At a moment of $\mathrm{t}=2.6 \mathrm{~ms}$, an obvious formation of $\mathrm{CH} 3$ is found in the cavity. The formation of $\mathrm{CH} 3$ attributes to the shear layer of fuel/air mixing and the high temperature region in the cavity as a result of combustion of pilot hydrogen. It is known that $\mathrm{CH} 3$ is one of 
the key radicals in the early period of ignition (the so called "induction" period), the significant formation of $\mathrm{CH} 3$ in the cavity indicates the benefits of cavity and pilot hydrogen for kerosene ignition. Figure 7 is time evolution of mass fraction of $\mathrm{OH}\left(Y_{\mathrm{OH}}\right)$. The initial distribution of $Y_{\mathrm{OH}}$ in the cavity is due to the pilot hydrogen. The mixing and ignition of kerosene change the $\mathrm{OH}$ distribution in the cavity. At $\mathrm{t}=5.6 \mathrm{~ms}$, peaks of $Y_{\mathrm{OH}}$ are located at the rear part of the cavity and also downstream of the cavity. The distribution of $Y_{O H}$ is consistent with the high temperature regions as shown in Figure 5.

The spatial feature of ignition and combustion of partially cracked kerosene is shown in Figure 8 giving contours of the consumption rate of $\mathrm{NC10H} 22\left(\omega_{\mathrm{NC} 10 \mathrm{H}_{22}}\right)$ as well as of the production rate of intermediate products: $\mathrm{CH} 3$, $\mathrm{C} 2 \mathrm{H} 2, \mathrm{CH} 2 \mathrm{O}$ and $\mathrm{CO}\left(\omega_{\mathrm{CH} 3}, \omega_{\mathrm{C} 2 \mathrm{H} 2}, \omega_{\mathrm{CH} 2 \mathrm{O}}, \omega_{\mathrm{CO}}\right)$ and of final product $\mathrm{CO} 2\left(\omega_{\mathrm{CO} 2}\right)$ at a moment of $\mathrm{t}=6.6 \mathrm{~ms}$. The peak of the negative value of $\omega_{\mathrm{NC10H} 22}$ (i.e. pyrolysis) appears downstream of the injection due to the local high temperature caused by jet/mainflow interaction and in the cavity due to the low flow velocity and high static temperature. The distributions of production rates of $\mathrm{CH} 3, \mathrm{C} 2 \mathrm{H} 2, \mathrm{CH} 2 \mathrm{O}, \mathrm{CO}$ and $\mathrm{CO} 2$ clearly show a spatial delay due to reaction mechanism. As indicated in Figure 8 (f), formation of $\mathrm{CO} 2$ is found to be located at most downstream positions, approximately 200 millimeters downstream of the injection point.

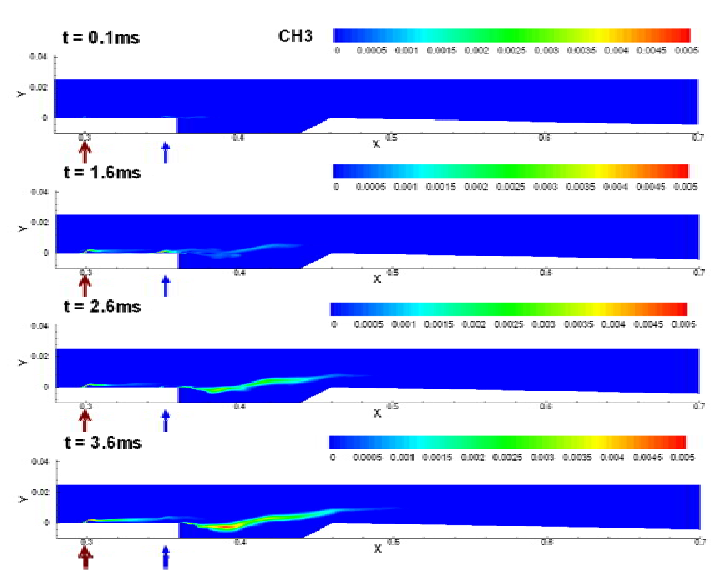

Figure 6 Time development of mass fraction of CH3

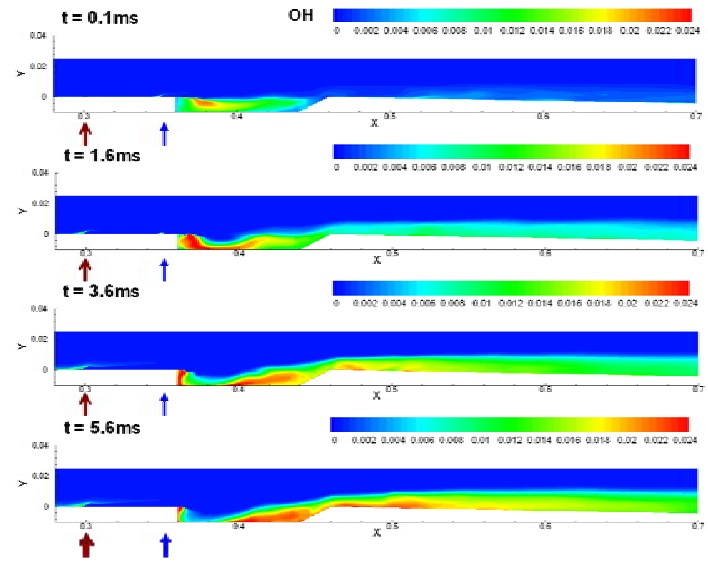

Figure 7 Time development of mass fraction of $\mathrm{OH}$

Contours of Mach number and density of the combustion flow at $t=6.6 \mathrm{~ms}$ are shown in Figure 9 (a) and (b). The bow shock appearing ahead of the fuel injection and its reflection from the above are well simulated. The reflected shocks observed downstream of the kerosene injection indicate that the present combustion is supersonic. Figure 10 gives distribution of the wall pressure (normalized by the static pressure at combustor inlet) along the combustor length with/without combustion. Significant pressure rise due to heat release of the combustion is found and the maximum pressure is more than twice of the inlet value. 

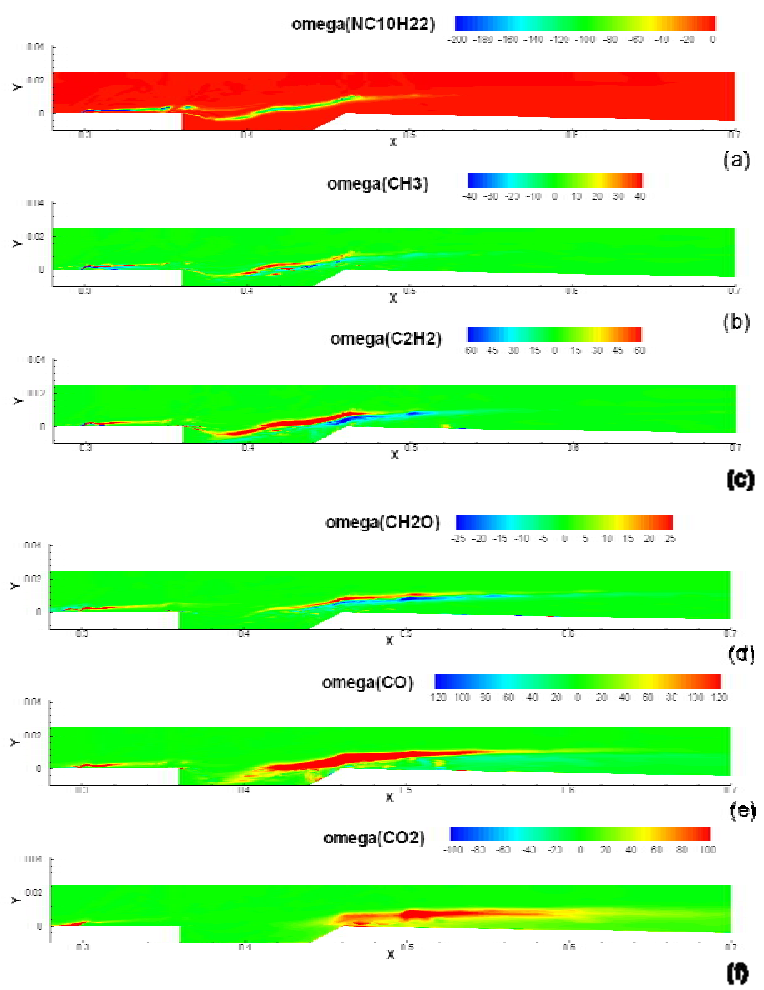

Figure 8 Distributions of consumption or formation rate of $\mathbf{n}$-decane, intermediate products and final product $\mathrm{CO} 2$ at $\mathrm{t}=6.6 \mathrm{~ms}$

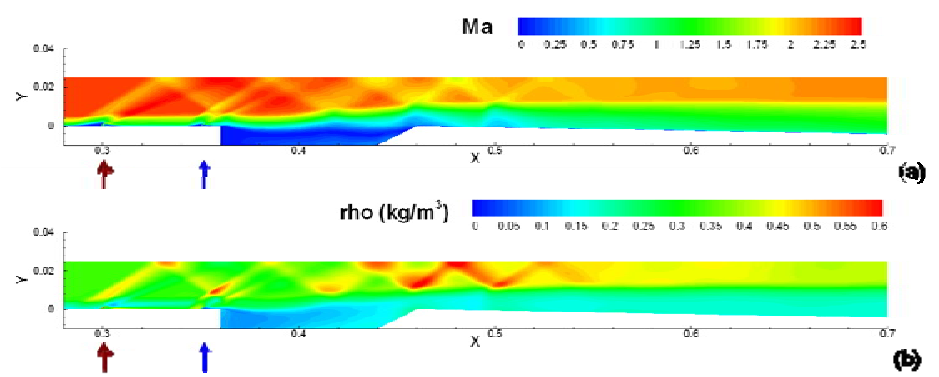

Figure 9 (a): Contours of the Mach number, (b): contours of the density after the flow is steady

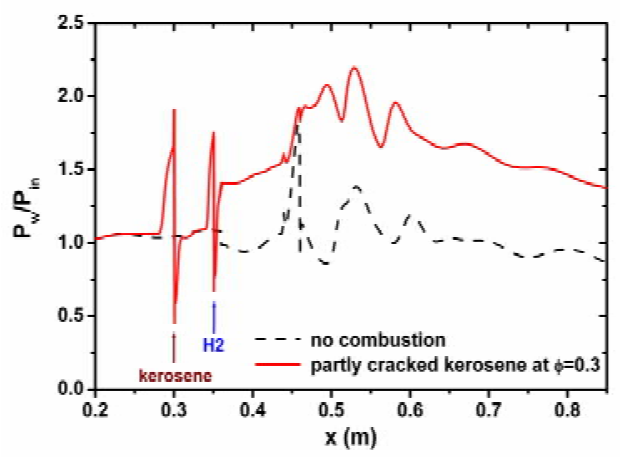

Figure 10 Distribution of the wall pressure with/without combustion 


\section{B. Ignition of uncracked kerosene}

Ignition of uncracked kerosene has been simulated with a total physical time of 8 milliseconds at present. The most important difference between uncracked and partially cracked kerosene is that formation of $\mathrm{CO}$ and $\mathrm{CO} 2$ of the uncracked kerosene lags largely behind that of the partially cracked fuel i.e. rate of heat release of the uncracked kerosene is much slower. Figure 11 and Figure 12 plot a time sequence of production rate of $\mathrm{CO} 2\left(\omega_{\mathrm{CO} 2}\right)$ for the partially cracked and the uncracked fuels respectively. As shown in Fig. 11 for the partially cracked kerosene, at $\mathrm{t}=$ $3.6 \mathrm{~ms}$, a significant formation of $\mathrm{CO} 2$ is found and at $\mathrm{t}=5.6 \mathrm{~ms}$ the formation of $\mathrm{CO} 2$ has been stable and ignition process comes to completion. Fig. 12, however, shows a quite different picture. At a moment of $t=5.6 \mathrm{~ms}$, formation of $\mathrm{CO} 2$ just starts to occur downstream of the cavity and a significant distribution of $\omega_{\mathrm{CO} 2}$ is not observed until approximately at $\mathrm{t}=7 \mathrm{~ms}$. Acceleration of $\mathrm{CO} 2$ production for the partially cracked kerosene case can be explained as follows.

The existence of $\mathrm{C} 2 \mathrm{H} 4$ due to cracking can promote the formation rate of formyl radical $\mathrm{HCO}$ via reaction as below (Eq. 1) and $\mathrm{HCO}$ can accelerate the production rate of $\mathrm{CO}$ and $\mathrm{OH}$ with reactions such as Eq. 2 and Eq. 3. Eventually, $\mathrm{CO}$ with $\mathrm{OH}$ or $\mathrm{O} 2$ turns to $\mathrm{CO} 2$.

$$
\begin{aligned}
& \mathrm{C} 2 \mathrm{H} 4+\mathrm{O}=\mathrm{CH} 3+\mathrm{HCO} \\
& \mathrm{HCO}+\mathrm{O}=\mathrm{CO}+\mathrm{OH} \\
& \mathrm{HCO}+\mathrm{OH}=\mathrm{CO}+\mathrm{H} 2 \mathrm{O}
\end{aligned}
$$

A perfectly stirred reaction model (PSR) by using the detailed kinetic mechanism is applied for confirmation of the above explanations. Figure 13 (a) and (b) show the time evolution of the radicals: $\mathrm{HCO}$ and $\mathrm{OH}$, and of the products: $\mathrm{CO}$ and $\mathrm{CO} 2$ for uncracked and $50 \%$ cracked kerosene. Compositions of the partially cracked fuel mixture and the fuel/air equivalence ratio are kept as the same as those of the simulation. The PSR initial temperature and pressure are chosen to be $1300 \mathrm{~K}$ and 1atm, typical values of flow conditions in the cavity during the ignition. As shown in the figure, formation of $\mathrm{HCO}$ for the uncracked fuel is much later than that of the partially cracked fuel and therefore, a much later production of $\mathrm{CO}$ and $\mathrm{CO} 2$.

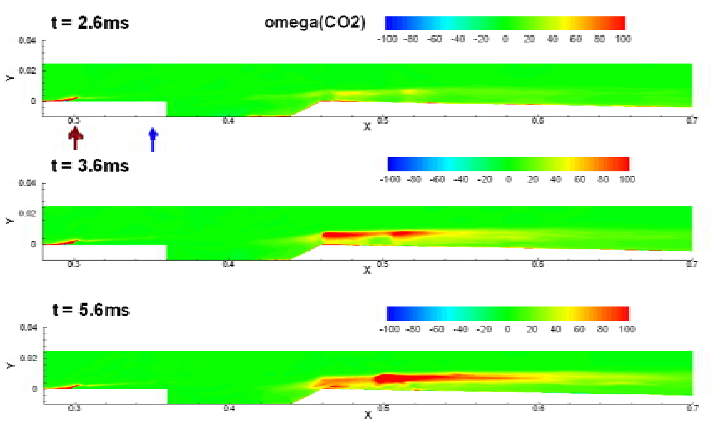

Figure 11 Time development of production rate of $\mathrm{CO} 2$ of the partly cracked fuel

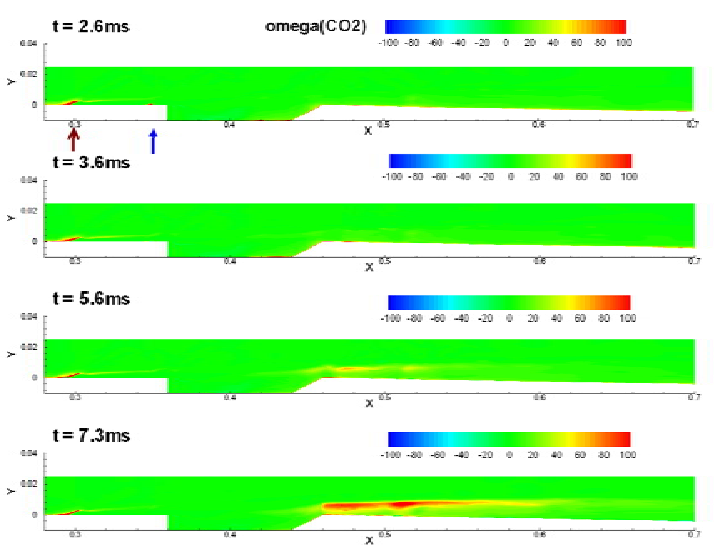

Figure 12 Time development of production rate of $\mathrm{CO} 2$ of the uncracked fuel 


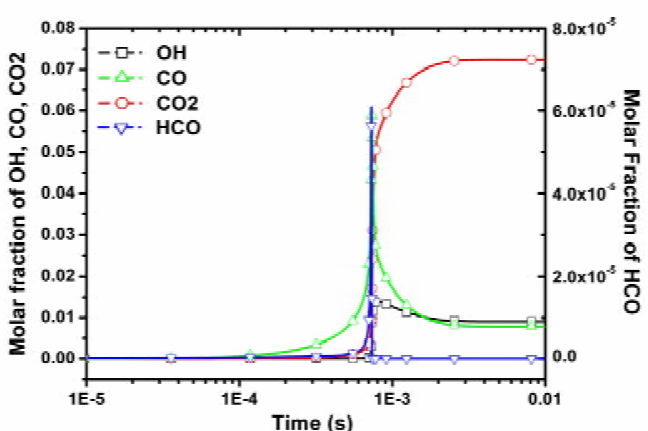

(a)

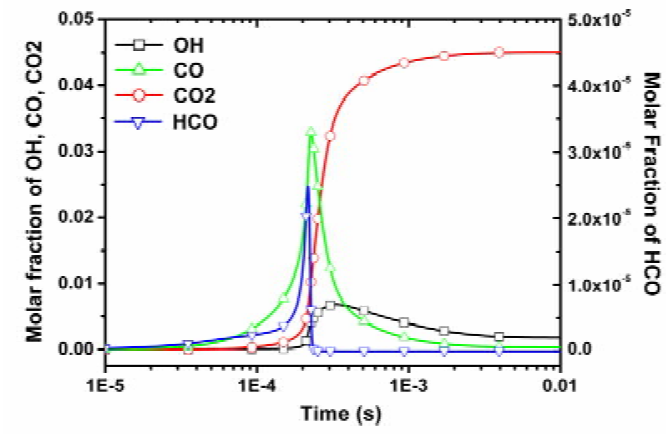

(b)

Figure 13 Analytical results obtained with PSR model and the detailed mechanism (a): molar fraction of $\mathrm{HCO}, \mathrm{OH}, \mathrm{CO}, \mathrm{CO} 2$ as a function of time for the uncracked fuel, (b): for the $50 \%$ cracked fuel

\section{Conclusions}

In the present study, unsteady process of ignition of partially cracked and uncracked kerosene in a Mach 2.5 supersonic combustor was studied numerically. The flow was solved by numerical scheme with good properties of upwind and shock capturing, as well as by the SST k- $\omega$ turbulence model with low Reynolds number and compressibility corrections. With quasi-steady-state assumption (QSS), the detailed kinetic mechanism proposed by P. Dagaut was reduced to be acceptable for multiple-dimensional computation. Eddy dissipation concept (EDC) of fully coupling flow solver and reactions was applied to model turbulence/chemistry interaction and In Situ adaptive tabulation (ISAT) technology used to speed up the computation.

Based on the present results, a few conclusions can be drawn:

1) Ignition of partially cracked kerosene is completed at a physical time of approximately $5.6 \mathrm{~ms}$ and a steady combustion is then established. However, for uncracked kerosene, the finish time of ignition is increased to more than 8 s.

2) Results of ignition of partially cracked kerosene indicate that combustion of pilot hydrogen provides a relatively high temperature region and a pool of radicals in the cavity and the ignition of kerosene mainly occurs at the aft ramp and downstream of the cavity (Fig. 5 and Fig. 7).

3) A spatial development of the fuel ignition was clearly shown by the present study, in which the formation of $\mathrm{CH} 3, \mathrm{C} 2 \mathrm{H} 2, \mathrm{CH} 2 \mathrm{O}$ in the cavity and the production of $\mathrm{CO}$ and $\mathrm{CO} 2$ at further downstream locations are observed (Fig. 8).

4) The acceleration of formation of $\mathrm{CO}$ and $\mathrm{CO} 2$ by the cracked products (ethylene, hydrogen) can be explained by the increased production in $\mathrm{HCO}, \mathrm{CH} 2 \mathrm{O}$ et al. due to the oxidation of ethylene (Fig.11, Fig. 12 and Fig. 13).

In the present study, 2-dimensional combustor is used as a model and three-dimensional effects especially the jet lateral spreading are not considered. A follow-up improvement of the numerical work is currently underway.

\section{Acknowledgments}

This work is funded by Natural Science Foundation of China under Contract No. 10672169 and 11172309. The authors would like to thank Professor Chih-Jen Sung of University of Connecticut for his support in this work.

\section{References}

[1] J. Hank, J. Murphy, R. Mutzman, “The X-51A Scramjet Engine Flight Demonstration Program”, AIAA 2008-2540, 15th AIAA International Space Planes and Hypersonic Systems and Technologies Conference, Dayton, Oh, 2008 
[2] C. C. Rasmussen, J. F. Driscoll, K-Y. Hsu, J. M. Donbar, M. R. Gruber, and C. D. Carter, "Stability limits of cavitystabilized flames in supersonic flow", Proceedings of the Combustion Institute, 30 (2005) 2825-2833

[3] J.-Y. Choi, F. Ma, V. Yang, "Combustion Oscillations in a Scramjet Engine Combustor with Transverse Fuel Injection", Proceedings of the Combustion Institute, 30 (2005) 2851-2858

[4] B. D. Hitch, E. D. Lynch, "Use of Reduced, Accurate Ethylene Combustion Mechanisms for a Hydrocarbon-Fueled Scramjet Simulation", AIAA2009-5384, 45th AIAA/ASME/SAE/ASEE Joint Propulsion Conference \& Exhibit, Denver, Colorado, 2009

-55] P. Gokulakrishnan, S. Pal, M.S. Klassen, A.J. Hamer, R.J. Roby, O. Kozaka and S. Menon, "Supersonic Combustion Simulation of Cavity-Stabilized Hydrocarbon Flames using Ethylene Reduced Kinetic Mechanism", AIAA2006-5092, 42nd AIAA/ASME/SAE/ASEE Joint Propulsion Conference \& Exhibit, Sacramento, California, 2006

[6] C. J. Montgomery, W. Zhao, C.-J. Tam, D. R. Eklund and J.-Y. Chen, "CFD Simulations of a 3-D Scramjet Flameholder Using Reduced Chemical Kinetic Mechanisms”, AIAA2003-3874, AIAA Computational Fluid Dynamics Conference, Orlando, Florida, 2003

[7] A. Rajasekaran, G. Satishkumar, V. Babu, "Numerical simulation of the supersonic combustion of kerosene in a model combustor", Progress in Computational Fluid Dynamics, 9(1) (2009) 30-42

[8] J. M. Tishkoff, J. P. Drummond and T. Edwards, "Future directions of supersonic combustion research - Air Force/NASA workshop on supersonic combustion", AIAA1997-1017, 35th Aerospace Sciences Meeting and Exhibit, Reno, NV, 1997

[9] P. Dagaut, "On the kinetics of hydrocarbons oxidation from natural gas to kerosene and diesel fuel", Phys. Chem. Chem. Phys., 4, (2002), 2079-2094

[10] B. F. Magnussen, B. H. Hjertager, "On mathematical modeling of turbulent combustion with special emphasis on soot formation and combustion", Proceedings of the Combustion Institute, 16(1), (1977), 719-729

[11] D. R. Sobel, L. J. Spadaccini, "Hydrocarbon Fuel Cooling Technologies for Advanced Propulsion", ASME Journal of Engineering for Gas Turbines and Power, 119, (1997) 344-351

-[12] T. Edwards, L. Q. Maurice, "Surrogate Mixtures to Represent Complex Aviation and Rocket Fuels", Journal of Propulsion and Power, 17 (2001), 461-466

-[13] F. Zhong, X. Fan, G. Yu, J. Li, and C-J. Sung, "Thermal Cracking and Heat Sink Capacity of Aviation Kerosene under Supercritical Conditions", Journal of Thermophysics and Heat Transfer, 25(3), (2011), 450-456

[14] M. S. Liou, C. J. Steffen, “A New Flux Splitting Scheme”, Journal of Computational Physics, 107 (1993) 23-39

[15] F. W. Spaid, E. E. Zukoski, "A study of the interaction of gaseous jets from transverse slots with supersonic external flows", AIAA Journal, 6(2), (1968) 205-212

[16] M. R. Gruber, R. A. Baurle, T. Mathur, and K-Y. Hsu, "Fundamental Studies of Cavity-Based Flameholder Concepts for Supersonic Combustors", AIAA 1999-2248, 35 ${ }^{\text {th }}$ AIAA/ASME/SAE/ASEE Joint Propulsion Conference and Exhibit, Los Angeles, CA, 1999

[17] S. B. Pope, "Computationally efficient implementation of combustion chemistry using in-situ adaptive tabulation", Combustion Theory and Modeling, 1 (1997) 41-63

-[18] X. Fan, G. Yu, J. Li, X. Zhang, and C-J. Sung, "Investigation of Vaporized Kerosene Injection and Combustion in a Supersonic Model Combustor", Journal of Propulsion and Power, 22(1), (2006) 103-110

[19] A personal communication with Dr. Chih-Jen Sung of University of Connecticut

[20] S. S. Penner, B. P. Mullins, "Explosions, Detonations, Flammability and Ignition”, Pergamon Pres, p.75

[21] H. Lander, A. C. Nixon, "Endothermic Fuels for Hypersonic Vehicles", Journal of Aircraft, 8(4), (1971) 200-207 